\title{
Journal of Addiction Research and Adolescent Behaviour
}

Rokhsareh Yazdanipour, J Addiction Research and Adolescent Behaviour

Doi: $10.31579 / 2688-7517 / 001$

The Role of the Ministry of Education in Preventing Sexual Crimes in Girls in Sari High School

\author{
Rokhsareh Yazdanipour ${ }^{1}$
}

${ }^{1}$ Master of Criminal Law and Criminology, Education Department of Sari, Sari.

Corresponding Author: Rokhsareh Yazdanipour, Master of Criminal Law and Criminology, Education Department of Sari, Sari, E-mail: yazdanipour1373@gmail.com.

Received date: May 25, 2018; Accepted date: June 28, 2018; Published date: July 09, 2018.

Citation this Article : Rokhsareh Yazdanipour, Therole of the Ministry of Education in preventing sexual crimes in girls in Sari high school, J Addiction Research and Adolescent Behaviour, Doi:10.31579/2688-7517/001

Copyright: @ 2018 Rokhsareh Yazdanipour This is an open-access article distributed under the terms of the Creative Commons Attribution License, which permits unrestricted use, distribution, and reproduction in any medium, provided the original author and source are credited.

\begin{abstract}
The aim of this study wasto find outthe causes of sexual crimesinhigh school girl students and the role of the Ministry of Education in providing appropriate practical solutions for early prevention, control and reduction of this social harm through families, parents, and related organizations.

Inthisstudy, using fieldresearch, on theonehand, thecharacteristics and problems of femalestudentsin their families and high schools were studied and, on the other hand, they examined the important role of the Ministry of Education by providing educational, educational and Cultural research for early prevention has been proposed to provide appropriate training models and suggestions. The field survey was conducted by setting up a questionnaire based on the Likert scale with 3.5, and with the approach of the Ministry's role in the prevention of sexual crimes, whose validity and reliability Has been done. Using a statistical compilation of 2855 high school female students, 340 female students were selected to complete this questionnaire. Questionnaire questions are divided into five different areas, with the Ministry's role in the prevention of sexual crimes approach, and completed by interviewing the student and using the appropriate statistical analyzes, the significance of each area is measured. To judge the hypotheses of this research (the effect of five different areas in the prevention of sexual offenses of students), one-sample statistical analysis was performed with P-Value criteria and Friedman's statistical test was used to compare the components of the five groups. Results of T Statistics of all groups are of higher priority than at leastacceptable, except for the groups of counseling programs. The value of the Tstatistic of each priority group is of importance for the prevention of sexual offenses. Therefore, the reduction of the T-statistic in this group could be due to this issue. Given the sovereignty of the Islamic country, religious deficits are less visible and necessary in the various activities of the community.
\end{abstract}

\section{Keywords}

Prevention, Ministry of Education, Sexual Offenses, Student Girls.

\section{Introduction}

Increasing the types of crimes and the emergence of new forms of delinquency is one of the problems of the current societies. But in addition, the more serious problem facing societies is the reduction of the juvenile offense and committing these crimes by the children and adolescents of the community, which, unfortunately, despite the various investigations and theories, continues to grow. Access to crime, such as the sale and consumption of narcotics and psychotropic drugs, assault, sexual offenses and such crimes into schools and the spread of it among students of different levels, has created a worrying situation and created a society It has made it difficult to take measures and to take precautionary measures. The Ministry of Education is the first large social institution that the child has set foot on. It has the greatest impact after the family in the child's soul. The child's social and cultural personality is based on this institution. Therefore, the attention should be paid to the officials and experts. It is clear that education in our country does not have a high status as a diminutive of crimes, or it is better to be told that they do not have such a position.
However, the educational and cultural roots of reducing crime can be searched and retrieved in this institution. Obviously, this institution is worthy of serious discussion and can be the main institution at the head of the target of this research, which is the knot of many problems of society. Therefore, education as the most influential institution and the only institution that can properly promote developmental education in the form of common educational training, should integrate sociological policies and religious teachings into new teaching for better law-making And the rights of the child and adolescent. The law also emphasizes the issue of the Ministry of Education's impact on students and their proper moral and judicial education (Section 3, Article 9, and Article 3 of the Constitution). In addition, this is stated in Article 1 of the Law on the Establishment of the Ministry of Education, and emphasizes that the delivery of children and young people in terms of the prosperity of talent and abilities to the extent that they can play an effective role in society. ,That is, the duty of education is left to the Ministry of Education. 
Therefore, it is essential for the Ministry of Education to work towards identifying these factors and planning precisely for early prevention of student crime in relation to the implementation of training classes, research workshops and advisory and scientific conferences to enrich this important field. Considering the sensitivity of adolescents' age and the vulnerability of adolescents, the recognition of adolescents and their unique characteristics and family and the conditions and the type of atmosphere dominated by it, as well as the interaction of these two components together, which can lead to the emergence and development of their talents, or that On the contrary, it is a matter of great importance to distracting and depriving adolescents of their talents and bringing about issues and consequences such as behavioral and social deviations such as delinquency.

Students form a huge stratum of the country's population. In all countries, the world in general and in our country, in particular, issues a wide range of schools, schools and universities and physical and psychological factors among students and students, and it seems that there are many factors of physical and mental health. Psychologically endangers them. It is inferred that a specific prevention policy will be adopted for these age groups in the policy of crime control. The goal of this policy is to reduce the number of delinquency cases in children and students, support them and prevent delinquency and correct them. Rajabi Poor (2008) conducted a study entitled "Student delinquency and the possibility of social prevention (from the viewpoint of education experts). A survey was conducted from 26 educational experts in the eastern and north-eastern parts of Tehran in 2006, all of which were conducted in 2006. These experts were from individuals who, in addition to executive responsibilities in education, had a history of education. The data were collected through a questionnaire consisting of several sections including individual characteristics, factors affecting juvenile delinquency, students' attitude to the police, the issue of police training and prevention from crime, the place of learning approach in education, social prevention and descriptive tests for data analysis. Koohi (1392) A study entitled "Youth and Social Damage" described the sociological explanation of the moral deviations of high school students in East Azarbaijan. The results show that the prevalence of moral deviations is moderately high. The results of correlation analysis show that there is a significant correlation between social capital, the status of components of psychological factors, the level of religiosity and communication skills with moral deviations.

Aliverdi Nia and Star (1392) conducted a study. The main objective of this research is to investigate the role of family, school, and peers in the crime of student delinquency in Mashhad. The research method is a survey and data collection tool is a questionnaire. The statistical population of the study consisted of high school students of 3rd high school in 5th district of Mashhad in the academic year of 1392-1392. A total of 400 students were selected through proportional stratified random sampling as a sample. The research framework is based on three theories of social linkage, social learning, and tagging. According to the research findings, the belief variable among male students had the highest ability to explain the delinquency. In contrast, among the female students, the differential bond has the most powerful explanatory power. These findings also show that the belief variable is the most important variable that can significantly explain and predict the changes in the dimension of property degradation, theft, material misconduct, and substance abuse. In the case of violence later, the differential variable has more predictive power than other variables. Ahmadi et al. (2009) conducted a study entitled "Factors Related to the Crime of High School Students". The results showed that the dependence of friends, religiousness and use of mass media had the most relationship with youth delinquency, respectively. Peer groups appear to be of great importance in strengthening the juvenile delinquency of their youth. Strengthening the religious identity of young people can help reduce crime rates. Together with these two, the reduction of violent content of mass media programs can, in particular, lead to a reduction in delinquency.
Behrebar et al. (2009), in a paper titled Crime Prevention through environmental design in schools, firstly, focused on the impact of crime and violence on students' mental and physical security, and the most effective measures to prevent crime in schools, Emotional actions such as training and modeling of normal social behaviors and effective coping with the grounds for the emergence of antisocial behavior and violence, instead of physical acts such as punishment.Tabatabaei and Aliin (2006) in Tehran, a research aimed at identifying major traumatic factors in the religious education of students in secondary schools in Tehran from the viewpoint of school principals. Findings of the research show that the school environment and the factors related to the school can be effective factors in the religious education of high school students in Tehran. Also, family and community are effective factors in religious education of secondary school students who have a negative attitude. They are responsible for religious education in this area.

A research entitled Social deviations in the mirror of research, by Golchin (2008), has been designed to find out the causes of deviant behavior and the causes or factors of social exclusion of youth and adolescents. The results indicate that juvenile delinquency is affected or related to factors such as gender, age, family base, parental religious level, the number of contacts with friends, deportation, education status, school attendance, The extent of the parent company is at the meetings of the Association and its coaches. In addition, the variables that have the most frequent confirmation in relation to the creation, establishment and strengthening of deviant behavior and juvenile delinquency include the following: socioeconomic status, The relationship between the teenager and the group of unmarried friends and the desire and membership in those groups, type and rate Elemental control and parental control of adolescent behavior and degree of disruption and disorientation. Doronabows et al. (2001) conducted a research on family and school relationships and their association with deviant behaviors of young people in communities and groups and concluded that families and schools were in a position to reduce youth diversions such as smoking, the use of alcohol, the use of marijuana, delinquency and other deviant behaviors have an important role. The program for the prevention of juvenile delinquency and the group approach to reducing delinquency in schools-Germany: In 1982, the program followed a compromise between education and police in Hamburg, Germany, in order to increase the resistance of students by focusing on providing information on the extent and Causes and prevention of juvenile delinquency. The program relies on volunteer officers who rebel in their leisure time classes. The program provides classes on staff discussions and methods and teaching methods for officers (Boutner, 2002). Tools such as videotapes about theft, violence and sabotage are available for elementary classes. The results of the evaluation of 300 students participating in the program showed that these programs have led to an increase in students' awareness of crime prevention. Threefourths of the students felt that they could put themselves at risk instead of the victim as well as the perpetrators.

According to the foregoing, the increasing incidence of sexual crimes in female students shows that traditional approaches to judicial and preventive prevention have not been effective. New findings on criminology, sociology ... on the causes of female students' Criminalization has proven the need for early prevention and development of delinquency. The aim of this study was to find out the causes of sexual crimes in high school girl students and the role of the Ministry of Education in providing appropriate practical solutions for early prevention, control and reduction of this social harm through families, parents, and related organizations.

\section{Research Methodology}

In this study, using field research, on the one hand, the characteristics and problems of female students in their families and high schools were studied and, on the other hand, they examined the important role of the Ministry of Education by providing educational, educational and Cultural studies for early prevention, the provision of appropriate educational models and suggestions. 
In this research, after accurate knowledge of the problem, the library, sources and articles, documents, and related documents were first studied and, after examining different types of models, The framework for work designation and scope has also been identified and the appropriate model has been selected and reviewed

1) Data collection that first identified the statistical population and determined the variables, scales and sample size, and then compiled the necessary information through sampling methods.

\section{2) Summarize data in statistical tables}

3) Analysis of data using graphs and statistical indices using statistical software

\section{4-Conclusion}

\section{Sampling}

It is worth noting that, based on studies in statistical literature, the choice of sample size depends on factors such as quantitative or qualitative variables, nominal, sequential or numerical, population size, and statistical distribution of the population. So, if the variables studied have two conditions, firstly, by studying a questionnaire with a five-point Likert scale (nominal qualitative variable), and secondly, the size of your statistical population is low, from the following formula to get the sample size from The equation (1) is used:

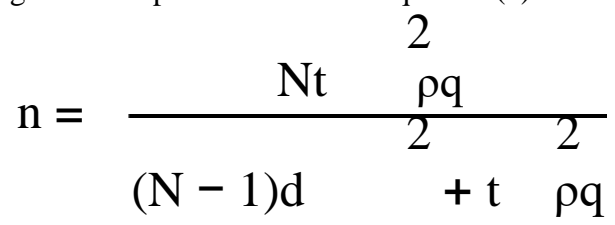

Here $\mathrm{n}$ is the required sample size (minimum number of inquiries) $\mathrm{N}$ The total population of the population, $\alpha$ is the $95 \%$ confidence level, $P$ is the success rate and $d$ is the acceptable measurement error, which is usually considered in the $5 \%$ research. In other words, with this sample size calculated from this formula, the accuracy of the information at $95 \%$ confidence level and $5 \%$ error is valid.

\section{Reliability and Validity}

In this research, the reliability coefficient obtained through Alpha coefficient using SPSS software is 0.84 and the alpha coefficient shows that the questionnaire used by the researcher is highly reliable. Also, with the advice of experts and statistical advisor, the questionnaire of this research (previously approved by its validity and papacy) is divided into five groups.After assessing the validity and reliability of the questionnaire in this study, a field survey was conducted using a Likert scale with a 3.5-point questionnaire and with the Ministry of Justice's approach to the prevention of sexual crimes. Using a statistical compilation of 2855 high school girl students in Sari, 340 girls were selected to complete this questionnaire. Questionnaire questions are divided into five different areas, with the Ministry's role in the prevention of sexual crimes approach, and completed by interviewing the student and using the appropriate statistical analyzes, the significance of each area is measured.

\section{Statistical analysis method}

One of the basic foundations of any research is the analysis of information. In this research, descriptive and inferential statistics were used to analyze the data. In this research, for statistical analysis, the statistical tests including the Kolmogorov-Smirnov test (to determine the normalities of data and abnormal data), the One-Sample Test and Friedman test was used.Because one of the single-sample t-test features is that when the number of samples increases to more than 30, its probabilities coincide exactly with the probability of normal distribution. Therefore, for tests with any number of samples, the test sample $\mathrm{H}$ can be used. Given the fact that the number of samples in this study was 340, this test was used reliably. Also, it is a question of comparing several groups in terms of their average ranking and whether these groups can be of a community or not?The scale in this test must be at least a rating. The same Friedman test (repeated sampling or analysis of variance of two classification classes). This test is used when it comes to examining the views of a group in a number of contexts, and based on the opinions of individuals in this group, the priority of each item is based on a meaningful ranking (or meaningful tendencies of individuals to each variables).

\section{Research findings}

\section{$\mathrm{T}$ single-sample test $\mathrm{t}$ group one}

Regarding the result of correlation coefficients, using the single-sample $t$ test, the impact of the "function of school administrators and deputies" on the prevention of sex offenders has been analyzed. Table (1) shows the results of the analysis. Because in this research, this criterion is less than 0.051 , there is sufficient reason to confirm the hypothesis of the impact of the first group

factors (the function of directors and deputies in schools) in preventing student sexual crimes as an important factor.

\begin{tabular}{|l|l|l|l|l|l|l|l|l|}
\hline & \multicolumn{2}{|l|}{ Test Value=3.5 } \\
\hline $\begin{array}{l}\text { Functional group of school } \\
\text { administrators and assistants }\end{array}$ & $\mathbf{N}$ & Mean & $\begin{array}{l}\text { Std.Devia } \\
\text { tion }\end{array}$ & $\begin{array}{l}\text { Std.Error } \\
\text { Mean }\end{array}$ & T & \multicolumn{2}{|l}{$\begin{array}{l}\text { (P-Value) } \\
\text { the Difference }\end{array}$} \\
\cline { 3 - 7 } & & & $\mathbf{0 . 5 3 0 0}$ & $\mathbf{0 . 0 2 8 7}$ & $\mathbf{1 4 . 2 6}$ & $\mathbf{3 . 8 9 8 5}$ & $\mathbf{3 . 9 2 3 5}$ \\
\hline
\end{tabular}

Table 1 shows the results of the single sample t of the first group components

\section{Single sample $t$ group II test}

Regarding the result of correlation coefficients, using the single-sample t-test, the role of teachers and interaction with students and their families has been analyzed in the prevention of sex offenders. Table 2 shows the results of the analysis. As this criterion is less than 0.051 in $001 / 02$, there is sufficient reason to confirm the hypothesis of the effect of the second group factors on the prevention of student sexual crimes as an important factor. Table 2 shows that, Among the analyzed groups, the highest T-statistic is in this group, which characterizes the importance of the components of this group.

\begin{tabular}{|l|l|l|l|l|l|l|l|}
\hline & \multicolumn{2}{|l|}{ Test Value=3.5 } \\
\hline $\begin{array}{l}\text { The role of teachers and } \\
\text { interaction } \begin{array}{c}\text { with students } \\
\text { and their families }\end{array}\end{array}$ & $\mathbf{N}$ & Mean & $\begin{array}{l}\text { Std.Deviatio } \\
\mathbf{n}\end{array}$ & $\begin{array}{l}\text { Std.Error } \\
\text { Mean }\end{array}$ & $\mathbf{T}$ & \multicolumn{2}{l|}{$\begin{array}{l}\text { (P-Value) } \\
\text { the Difference }\end{array}$} \\
\cline { 2 - 8 } & $\mathbf{\text { Lower }}$ & & Upper \\
\hline
\end{tabular}

Table 2: showsthe results of the single sample t component of the second group 


\section{T single-sample test $\mathrm{t}$ group III}

Regarding the result of correlation coefficients, using the single-sample $t$ test, the group "The role of psychological counselors" has been analyzed in the prevention of student sexual crimes. Table 3 shows the results of the analysis. As the benchmark is less than 0.05 in 001 , this is a sufficient reason to confirm the hypothesis of the impact of third-party agents on the prevention of student sexual abuse as an important factor.

\begin{tabular}{|c|c|c|c|c|c|c|c|c|}
\hline \multirow{3}{*}{ The role of psychologists } & \multicolumn{8}{|c|}{ Test Value $=3.5$} \\
\hline & \multirow[t]{2}{*}{$\bar{N}$} & \multirow[t]{2}{*}{ Mean } & \multirow[t]{2}{*}{ Std.Deviation } & \multirow[t]{2}{*}{$\begin{array}{l}\text { Std.Error } \\
\text { Mean }\end{array}$} & \multirow[t]{2}{*}{$\mathbf{T}$} & \multicolumn{2}{|c|}{ Difference } & \multirow{2}{*}{$\begin{array}{l}\text { (P-Value) } \\
\text { Sig. (2-tailed) }\end{array}$} \\
\hline & & & & & & Lower & Upper & \\
\hline & 340 & 3.7200 & $\overline{0.7200}$ & 0.0390 & $\overline{5.630}$ & $\mathbf{3 . 7 8 7 2}$ & $\overline{3.7968}$ & $\ldots$ \\
\hline
\end{tabular}

Table 3 shows the results of the single sample t of the third group components

\section{Single sample t group IV}

Regarding the results of correlation coefficients, using the single-sample $t$ test, the "Educational Planning" group has been analyzed in the prevention of sex offenders. Table 4 shows the results of the analysis. Because in this research, this criterion is less than $0.05 \%$, there is sufficient reason to confirm the hypothesis of the impact of group 4 factors on preventing student sex crimes as an important factor.

\begin{tabular}{|c|c|c|c|c|c|c|c|c|}
\hline & \multicolumn{8}{|c|}{ Test Value $=3.5$} \\
\hline \multirow[t]{2}{*}{$\begin{array}{l}\text { Educational } \\
\text { Planning Group }\end{array}$} & \multirow[t]{2}{*}{$\mathbf{N}$} & \multirow[t]{2}{*}{ Mean } & \multirow[t]{2}{*}{ Std.Deviation } & \multirow[t]{2}{*}{ Std.Error Mean } & \multirow[t]{2}{*}{$\mathbf{T}$} & \multicolumn{2}{|c|}{ 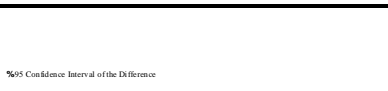 } & $\begin{array}{l}\text { (P-Value) } \\
\text { Sig. (2-tailed) }\end{array}$ \\
\hline & & & & & & Lower & Upper & \\
\hline & 340 & 3.9100 & 0.5300 & 0.0287 & 14.26 & 3.8041 & $\mathbf{3 . 8 2 3 5}$ & ..m. \\
\hline
\end{tabular}

Table 4 shows the results of the single test $t$ of the fourth group components

\section{One-sample test t fifth group}

Regarding the results of correlation coefficients, using the single-sample t test, the group "Educational counseling programs" has been analyzed in the prevention of sex offenders. Table 5 shows the results of the analysis. Because in this research, this criterion is less than 0/0000, there is sufficient reason to confirm the hypothesis of the Fifth Factor Impact on Student Sex Crime Prevention as an important factor.

\begin{tabular}{|c|c|c|c|c|c|c|c|c|}
\hline & \multicolumn{8}{|c|}{ Test Value $=3.5$} \\
\hline \multirow{2}{*}{$\begin{array}{l}\text { Advisory } \\
\text { Group } \\
\text { Programs }\end{array}$} & \multirow[t]{2}{*}{$\bar{N}$} & \multirow[t]{2}{*}{ Mean } & \multirow[t]{2}{*}{ Std.Deviation } & \multirow[t]{2}{*}{\begin{tabular}{|l|} 
Std.Error \\
Mean
\end{tabular}} & \multirow[t]{2}{*}{$\mathbf{T}$} & \multicolumn{2}{|c|}{ Difference } & \multirow{2}{*}{$\begin{array}{l}\text { (P-Value) } \\
\text { Sig. (2-tailed) }\end{array}$} \\
\hline & & & & & & Lower & Upper & \\
\hline & 340 & 3.2600 & 0.7100 & 0.0385 & -6.23 & 3.8985 & 3.9235 & am \\
\hline
\end{tabular}

Table $\mathbf{5}$ shows the results of the single sample $t$ of the fifth component

Table 5 shows that the amount of $\mathrm{T}$ statistics related to the analysis of the impact of educational counseling programs on the prevention of sex offenders was negative. This result could be due to the fact that the programs of advisers educated on the religious beliefs of students and their families did not have much effect; in this regard, more modern programs, more efficient and necessary activities should be done according to the current conditions of the society, which are filled with hordes We face false data in conducting and virtual spaces, and it is often referred to as the juvenile and youths, by the relevant organizations, in particular the Ministry of Education.

\section{Fried man test results, for comparison of 5 groups of selected components}

The Friedman statistical test was used to compare the components of importance for intervention. According to the results presented below, no significant difference was observed between the priority groups among the components of the components. Table 6 shows the results of Friedman test. The coverage of the test statistic has been calculated. This value is calculated as 0.832 in this test. Because this is more than $5 \%$ (0.832), with $95 \%$ confidence, the importance of equalizing the importance of the 5 components of the group as a priority in preventing student sexual crimes can be concluded. Chart (1) shows the changes in the five groups of components of this study.

\begin{tabular}{|c|c|}
\hline \multicolumn{2}{|c|}{ Mean Rank' } \\
\hline Group 1 & $\mathbf{2 . 7 5}$ \\
\hline Group 2 & $\mathbf{3 . 7 5}$ \\
\hline Group 3 & $\mathbf{2 . 8 8}$ \\
\hline Group 4 & $\mathbf{3 . 1 3}$ \\
\hline Group 5 & $\mathbf{2 . 5}$ \\
\hline
\end{tabular}

Table 6 Friedman test results 


\section{Comparison of components in importance for intervention}

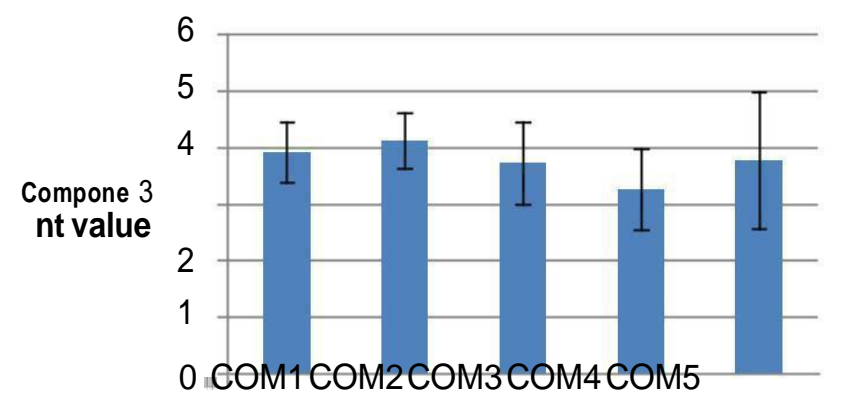

Group

Chart (1) shows the changes in the five groups of components of this study.

\section{Conclusion}

The aim of this study was to find out the causes of sexual crimes in high school female students and the role of the Ministry of Education in providing appropriate practical solutions for early prevention, control and reduction of this social hazard through families, parents, and related organizations. Existing variables In this research, the questions were evaluated by the questions included in the questionnaire. The results of this hypothesis test showed that by presenting and implementing educational, educational and psychological programs based on individual factors effective in early prevention of students 'crimes and environmental factors, appropriate and appropriate to the students' conditions and taking into account their differences Sexual crimes in high school girls should be reduced. Also, providing the latest and most accurate information about the consequences of the sexual deviations and crimes provided for in the Criminal Code and the criminology of students and raising public and individual awareness will reduce these types of crimes.

Results of the T statistics All five high-grade groups are more than at least acceptable, except for the fifth group (planning consultants). The value of the T-statistic of each priority group is of importance for the intervention and prevention of sexual crimes. However, unlike the four analyzes of groups one to four, which are of higher importance than the minimum acceptable, the value of the T-statistic for analyzing the effect of the program Educational advisers were advised to prevent sex offenders. This result could be due to the fact that the programs of advisers educated on the religious beliefs of students and their families did not have much effect; in this regard, more modern programs, more efficient and necessary activities should be done according to the current conditions of the society, which are filled with hordes We face false data in conducting and virtual spaces, and it is often referred to as the juvenile and youths, by the relevant organizations, in particular the Ministry of Education.

Also, the results of the analysis of different groups indicate that the role of teachers and their interaction with students and their families is the most important factor for early intervention and prevention of sexual crimes in high school girl students. Also, by enhancing the role of teachers in communicating with students in order to increase general and individual awareness and motivating them to increase the standard social beliefs in students, this kind of crime will be reduced and prevented more effectively. Therefore, given the important role of teachers in preventing student delinquency, it seems that the necessary material and spiritual support should be given more attention to teachers who, without worrying, play their educational role in schools. This upgrade The position of teachers requires a support program through the Ministry of Education.
Also, the results of the analysis of different groups indicate that the function of school administrators and assistants due to constant problems with students 'problems after teachers has the greatest impact on creating a high security environment for the prosperity of students' potential talent. This seems to be the case. Continuing education courses and counseling for directors and vice-presidents for a conscious and compassionate approach to thinking and attraction of students is essential. Further, this process will prevent isolation of students and more powerful communication with them to express their problems.

Today, it's unclear to anyone that human societies require different counseling because of the varied complexity of the life of a machine. This advice is, of course, very important in teenagers and young people, especially in girls, due to special circumstances. The results of the group analysis of the role of psychologist's advisors showed that this factor influences the prevention of sexual crimes in the teenage and young age students. Therefore, it is essential to continue the school counseling program and the proper support of the victimized students, and efforts to restore their personality are essential. Therefore, focusing on juvenile delinquents and providing appropriate strategies to prevent them from returning to crime can be Have a great impact in preventing crime in schools. Also, the results of the analysis of the educational curriculum group indicate that increasing student awareness of sexual crimes and the consequences of sexual deviance can have a significant effect on students' mental health. Improving the social skills of students by providing education programs by educators and empowering students to support themselves against problems, especially sexual ones, can be a deterrent to sexual crimes. It is important to note that teachers of educational affairs Along with community change, they need to raise their level of individual awareness and empowerment by participating in training, service and inter-sectoral courses with relevant organizations (such as the judiciary).The fifth group analysis of breeding counseling programs showed that it had the least impact on the prevention of sexual offenses. This result could be due to the fact that the programs of advisers educated on the religious beliefs of students and their families did not have much effect; in this regard, more modern programs, more efficient and necessary activities should be done according to the current conditions of the society, which are filled with hordes We face false data in conducting and virtual spaces, and it is often referred to as the juvenile and youths, by the relevant organizations, in particular the Ministry of Education.

The summing up of statistical tests shows that by promoting the role of teachers in communicating with students in order to increase general and individual awareness and motivating them to increase the standard social beliefs in students, this kind of crimes is reduced and prevented more effectively. Gets Therefore, given the important role of teachers in preventing student delinquency, it seems that the necessary material and spiritual support should be given more attention to teachers who, without worrying, play their educational role in schools. This upgrade The status of teachers requires a support program through the Ministry of Education. Also, the cooperation of all relevant and influential institutions, in particular the Ministry of Education, in the plans for controlling and controlling the perpetrators, for which these crimes are foreseen, Reduce thesecrime.

\section{Acknowledgments}

I would like to express my sincere thanks and appreciation to the staff of the Education Offices of District 1 and 2 of Sari, who helped me in this research.

\section{References}

1. Iranmanesh, Nasim, (2005), Using the Principles of Prevention of Crimes through Environmental Design and its Overview in Iran, Tehran, Journal of Housing and Revolution, No. 110.

2. Manian, Mohammad Reza and Mahmoudinejad, Hadi (2009), Security and Urban Design, Publications: Haleh, First Edition. 
3. Bayat Rostami, Rouhollah, (2010), Spatial Analysis of Delinquency Patterns in the Central City of Cities Using the Geographic Information System (GIS) Case Study: Theft Victim in the Central District of Zanjan, Master's Thesis for Geography and Urban Planning, Zanjan University.

4. Beat, Bahram (2008), Explaining the Knowledge of Society and the Harmfulness of People in Iran (with Emphasis on the Role of Socio-Social Psychology), Journal of Social Sciences, No. 16.

5. Kalantari, Mohsen and Tavakoli, Mahdi (2007), Identification and analysis of urban crime centers, Journal of crime prevention studies, Journal of Police Prevention Police, Second Year, Second Edition, p. 75.

6. Statistics Center of Iran (2011), Results of Population and Housing Census, 2011.

7. Ebrahimi, Shahram (1387). Prevention of Human Rights Changes, Human Rights Researcher, Faculty of Social Sciences, Tehran University.

8. Ardebili, Mohammad Ali (2005), General Penal Law, Tehran, Publishing.

9. Social Pathology and Sociology of Deviations, Mohammad Hossein Farjad, Tehran Badr Publishing House (1992).

10. Social Pathology and Sociology of Deviations, Hedayatollah Sotoudeh, Tehran University Press (1996).

11. Ansel, Marc (1375). Social defense Translated by Assuri, Mohammad and Ali Hossein Najafi Obrandabadi, Tehran: Tehran University Press, Third Edition.

12. Aisenick, H.J. (1977) Crime and Personality; Translation by Pasha Sharifi, Hassan and Najafi Zand, Tehran, Rahnama Publication, 1996.

13. Bazargan, Zahra (2007), Mediation at School, Methods for Improving Students' Behavior, School Publications.

14. Bazargan, Zahra (2010), School Conflict Management, Successful World Experience, Sokhan Publishing.

15. Bazargan, Zahra (1391), Bullying in Schools, Iran's Perspective, No. 76, D \& Feb 2012.

16. Bazargan, Zahra (1393), to end the violence in school, in the hands of publication, Sokhan Publishing.

17. Bukhara'i, Ahmad (2011), Social deviations in Iran, Tehran, Pajhwok society.

18. Boston, John (2005), Approaches to Full Degree of Investigation, Translated by Hassan Pasha Sharifi, Al-Ghani, Tehran, Growth.

19. Behlavi, Yousef, Mansourian, Mohammad Karim (2006), Relationship between population density and the amount and type of crime, Journal of Social Welfare, Vol. 6, No. 22.

20. An Individual Prevention, Zaha Maddiehka, Fasa, (2010), Assessing National Security Threats on the Northern Borders of Iran, Amiyah Geographic Quarterly 9.

21. Hamzahlou, Zohreh and Akram Gheibi, 1394, Explaining the role of schools in preventing adolescents' Internet harms, National Conference on Knowledge and Technology of Educational Sciences, Social Studies and Psychology of Iran, Tehran, Institute for the Development of Knowledge and Technology Centers in Iran.

22. Khosroshahi, the power of ... (1388). Secondary prevention of crime and deviation in the teachings of the Quran. Journal of Social Welfare Research, Ninth Year, No. 34.
23. Ghanafrrd, Hasan; Alwani, Seyyed Mehdi and Azar, Adil (2009), Methodology of Research in the Field of Mathematics: An Approach, Publisher: Eshraghi, Saffar.

24. Rezaei, Shahgali and Samad Ramzi Ghareh Ghashlaghi, 1394, Studying the role of schools and media in preventing addiction, Second National Conference on Sustainable Development in Educational Sciences and Psychology, Social and Cultural Studies, Tehran, Islamic Studies and Research Center, Soroush Hekmat Mortazavi , Mehr Arvand Institute of Higher Education, Center for Sustainable Development.

25. Rajabi Poor, Mahmoud, Student delinquency and the possibility of socially preventative growth (from the viewpoint of education experts), The Journal of Police Knowledge, The Journal of Police Science, Vol. 10, No. 2, Summer 2008, p. 128 to p. 151).

26. Zandi, Veria (2009), Crime Prevention through Environmental Design in Residential Developments, Sanandaj, National Conference on Urban Development, Islamic Azad University, Sanandaj Branch.

27 Sarurizadeh, Amin and Reza Afhami, 2014, Crime Prevention through Environmental Design, A Strategy for Achieving Social Stability, Second International Congress on the Construction, Architecture and Urban Development, Tabriz, Permanent Secretariat of the International Congress on Structural Engineering, Urban Architecture and Development.

28. Sierra Faraz, Mohammad, Prevention of Crime and the Behavior of the Establishment of the Immune Society- Tehran; Publishing of the City of 1388 .

29. Shahabi Moghadam, Parvin, 1394, Performance of Educational Centers in Control of Social Violence of Students, Third Scientific Conference on Educational Sciences and Psychology of Social and Cultural Dangers in Iran, Qom, Islamic Studies and Research Center, Soroush Hekmat Mortazavi.

30. Qassari, Mohammad, Bazargan, Mohammad and Norouzi, Bahram (1392). Designer of a community-based police system with an emphasis on crime prevention. Police and Security Research Journal, Year 6, Number 2.

31. Clarkoodigaran (1388). Criminology Detection, 60 Practical Examples for Advocacy, Translated by the Ministry of Education and Science, Tehran, Public Authorities of the General Staff of the Islamic Republic of Iran.

32. Mohammadi Kani Saran, Mohammad Sedigh and Hasan Babaei, 2013, Investigating the Role of Environmental Design in Preventing Crime, Case Study: Sanandaj Defensive Spaces, National Conference on Urban Architecture and Humanities, Qazvin, Qazvin Azad University, Qazvin.

33. Mohammadzadeh, Omid; Ahmad Gharar; Fatemeh Basbar and Jafar Ghiyasipour, 1393, Study of sociological causes of delinquency in high school students in Ilam, International Conference on Humanities and Behavioral Studies, Tehran, Institute of Managers of the Vida Institute of Ideas.

34. Mostafavi, Seyed Javad and Ali Tal'zari, 1394, Analysis and ranking of environmental factors affecting crime, A case study of Gorgan city, National conference on architectural engineering, Civil engineering and physical development, Kohdasht, Kuhdasht municipality. 